\title{
Efeitos da Suplementação de Creatina na Captação de Glicose em Ratos Submetidos ao Exercício Físico
}

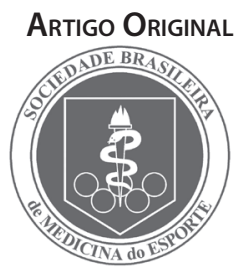

\section{Effects of Creatine Supplementation on Glucose Uptake in Rats Submitted to Exercise Training}

\begin{abstract}
Thiago Onofre Freire
Bruno Gualano²

Marco Dias Leme ${ }^{2}$

Viviane Ozores Polacow

Antonio Herbert Lancha Jr²

1. Centro de Ciências da Saúde / Universidade Federal do Recôncavo da Bahia (UFRB) e Instituto de Biologia (IB) / Universidade Estadual de Campinas (UNICAMP)

2. Departamento de Biodinâmica do Movimento Humano / Laboratório de Nutrição Aplicada à Atividade Motora da Escola de Educação Física e Esporte da Universidade de São Paulo.
\end{abstract}

\section{Endereço para correspondência:}

Rua do Cajueiro, s/n. Campus da UFRB. CEP 44570-000 - Santo Antônio de Jesus - Bahia - Brasil. Telefone / Fax: 55-75-3632- 4629. E-mail: thiagonofre@yahoo.com.br

Submetido em 04/01/2008 Versão final recebida em 08/03/2008 Aceito em 04/04/2008

\begin{abstract}
RESUMO
Estudos recentes têm sugerido que a suplementação de creatina é capaz de modular a homeostase da glicose, aumentando sua captação pelos tecidos periféricos. O objetivo deste trabalho foi investigar o efeito da suplementação de creatina na tolerância à glicose e no conteúdo de glicogênio muscular e hepático em ratos submetidos ou não à atividade física por quatro e oito semanas. Ratos Wistar foram divididos em dois grupos: quatro e oito semanas de intervenção. Posteriormente, cada grupo foi subdividido em quatro subgrupos, de acordo com a ingestão do suplemento e o treinamento: controle cedentário, controle treinado, suplementado sedentário e suplementado treinado. Os animais tiveram livre acesso à água e ração; o grupo suplementado teve $2 \%$ de sua ração sob a forma de creatina monoidratada. Os grupos exercitados nadaram 40 minutos por dia, quatro dias por semana, com carga entre 2 e $5 \%$ do seu peso amarrado ao peito. Após quatro e oito semanas, o teste oral de tolerância à glicose e as dosagens de glicogênio muscular e hepático foram realizadas. Não foram observadas diferenças significativas entre os grupos no teste de tolerância oral à glicose e no conteúdo de glicogênio muscular e hepático. Este estudo mostrou que a suplementação de creatina não exerceu influência na tolerância à glicose nem nas concentrações de glicogênio em ratos submetidos ou não à atividade física por quatro ou oito semanas.
\end{abstract}

Palavras-chave: àcido $\alpha$ metil guanidino acético, condicionamento físico, glicemia.

\begin{abstract}
Recently, studies have suggested that creatine supplementation can modulate glucose homeostasis by increasing glucose uptake in peripheral tissues. The aim of this study was to investigate the effects of creatine supplementation on glucose tolerance, muscle and hepatic glycogen content in rats submitted or not to physical activity for four and eight weeks. Wistar rats were divided in two groups: four and eight weeks of intervention. Afterwards, each group was subdivided in four subgroups, according to supplement intake and exercise: Sedentary Control; Trained Control; Supplemented Sedentary; and Supplemented Trained. The animals had free access to water and chow and the supplemented groups had two \% of their diet as creatine monohydrated. The exercise groups swam for 40 minutes a day, four days a week, with two to five $\%$ of their body weight attached to their chests. After four and eight weeks, oral glucose tolerance tests were performed and both hepatic and muscle glycogen were determined. No significant differences were observed between groups on glucose tolerance and glycogen content in muscle and hepatic tissue. This study shows that creatine supplementation does not influence neither glucose tolerance nor glycogen concentrations in rats submitted or not to physical activity for four and eight weeks.
\end{abstract}

Keywords: glycine, N-(aminoiminomethyl)-N-methyl-, physical fitness, blood glucose.

\section{INTRODUÇÃO}

A suplementação de creatina tornou-se popular por sua capacidade de aumentar o desempenho no exercício(1). Recentemente, essa amina tem sido investigada como uma possível ferramenta capaz de modular o metabolismo dos carboidratos. Ferrante et al.(2), por exemplo, demonstraram que a suplementação de creatina retardou significativamente o aparecimento de diabetes em ratos tipicamente hiperglicêmicos. Nosso grupo relatou que a suplementação de creatina, quando aliada ao treinamento aeróbio, também é capaz de melhorar a tolerância à glicose em humanos saudáveis ${ }^{(3)}$

Há grande controvérsia quanto a suplementação de creatina poder afetar a captação de glicose por efeito direto sobre o tecido periférico ou por aumentar a secreção pancreática de insulina ${ }^{(4)}$. Rooney et al. ${ }^{(5)}$, por exemplo, observaram hiperinsulinemia em camundongos submetidos à suplementação de creatina, mas não verificaram aumento no conteúdo de glicogênio muscular. Em contrapartida, OP'T Eijnde et al. ${ }^{(6)}$ 
demonstraram aumento de 40\% no conteúdo de glicogênio muscular a despeito da ausência de hiperinsulinemia.

Em relação ao efeito no tecido periférico, Jeong-Sun et al. ${ }^{(7)}$ demonstraram que a suplementação de creatina aumentava a expressão gênica do transportador de glicose muscular (GLUT-4) e de seus fatores de transcrição, o que contribuiria para o maior transporte de glicose para dentro da célula. Em humanos, após duas semanas de imobilização de uma das pernas, a suplementação de creatina contribuiu para manter o conteúdo de GLUT-4 no músculo imobilizado, enquanto no grupo controle esse mesmo parâmetro foi reduzido em 20\%(6). Nesse mesmo estudo, após 10 semanas de reabilitação muscular, o conteúdo de GLUT-4 no grupo suplementado aumentou $40 \%$ em relação ao grupo placebo. Em estudo com metodologia semelhante, Derave et al. ${ }^{(8)}$ também observaram aumento significativo nos conteúdos de GLUT-4 e glicogênio como conseqüência da suplementação de creatina em seis semanas de treinamento (reabilitação muscular). No entanto, ao analisarem a perna não exercitada, os autores constataram que a suplementação de creatina per se não foi capaz de induzir as mesmas adaptações. Diante disso, eles sugeriram que a creatina exerceria apenas um efeito sinérgico ao treinamento físico.

Apesar dessas evidências iniciais, alguns autores falharam em demonstrar a influencia da suplementação de creatina na homeostasia da glicose. Newman et al. ${ }^{(9)}$ demonstraram que a suplementação de creatina por 28 dias não afetou a tolerância à glicose em homens saudáveis. Além disso, diversos autores não conseguiram confirmar hiperinsulinemia após a ingestão de creatina ${ }^{(3,9)}$. De fato, ainda restam dúvidas sobre a suplementação de creatina ser capaz de influenciar os conteúdos de GLUT-4 e glicogênio muscular ${ }^{(10)}$. Logo, mais estudos são necessários para esclarecer quais os reais efeitos da suplementação de creatina na homeostasia da glicose.

O objetivo deste trabalho é investigar os possíveis efeitos da suplementação de creatina na tolerância à glicose e nos estoques de glicogênio muscular e hepático em ratos submetidos ou não à atividade física por quatro e oito semanas.

\section{MÉTODOS}

\section{Animais}

Esse estudo foi aprovado pelo comitê de ética em pesquisa da Escola de Educação Física e Esporte da Universidade de São Paulo (EEFEUSP). Ratos machos Wistar, obtidos no Instituto Butantã, foram divididos aleatoriamente em dois grupos: quatro e oito semanas de intervenção. Posteriormente, cada grupo foi subdividido em quatro subgrupos, de acordo com a ingestão do suplemento e do treinamento: controle sedentário, controle treinado (CT), suplementado sedentário (SS) e suplementado treinado (ST). Todos os ratos foram alocados em caixas (dois ou três animais por caixa), em ciclo claro/ escuro de 12 horas invertido e tiveram livre acesso à água e ração (Labina" / Purina).

\section{Desenho experimental}

Como descrito na figura 1, duas semanas antes da intervenção propriamente dita, os ratos que seriam suplementados com creatina iniciaram um processo de adaptação para ingerir a ração em pó, enquanto os animais que seriam submetidos ao treinamento iniciaram uma adaptação às condições de natação. A intervenção começou numa segunda-feira, quando todos os ratos foram pesados em balança de precisão (Filizola ${ }^{\circ}$, Santos, SP). Os grupos submetidos ao exercício nadavam 40 minutos por dia, quatro dias por semana (segunda, terça, quinta e sexta-feira) carregando uma carga amarrada ao seu tórax, com peso variável de 2 a 5\% da sua massa corporal. Desde o início da intervenção, os ratos eram pesados semanalmente (sempre às segundas-feiras) e a sobrecarga de treino era ajustada. A temperatura da água foi mantida em $31^{\circ} \mathrm{C}$ e os ratos foram enxugados após o exercício, antes de retornar às caixas. $O$ grupo suplementado tinha creatina adicionada à ração na razão de $2 \%$.

Quatro e oito semanas após o inicio da intervenção, o teste oral de tolerância à glicose (TOTG) foi realizado nos respectivos grupos. Após uma noite de jejum, uma amostra de sangue foi retirada da veia caudal de cada rato (tempo 0), que na seqüência recebia, via gavagem, uma solução de glicose na concentração de dois gramas de glicose por quilograma de peso. As amostras de sangue foram coletadas nos tempos de 30, 60, 90 e 120 minutos. Após o TOTG, os ratos retornaram a suas caixas e tiveram acesso à ração por 24h, quando então foram sacrificados por decapitação. A amostras de tecidos do músculo gastrocnêmico e fígado foram retiradas e congeladas em nitrogênio liquido imediatamente, para posterior análise.

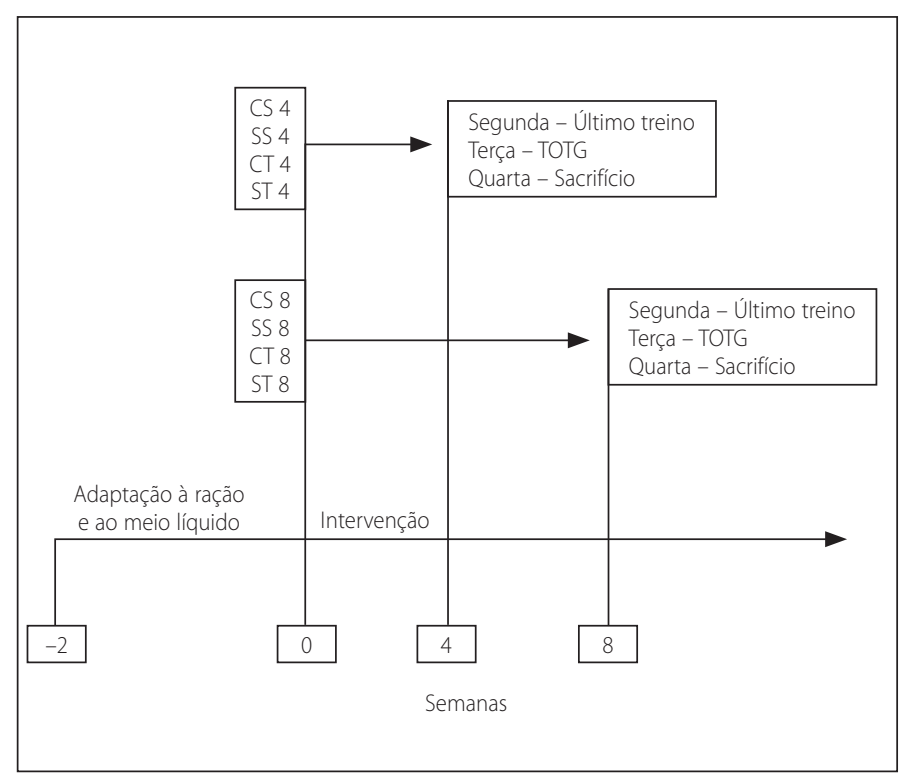

Figura 1. Desenho experimental. Grupos: controle sedentário semana $4(\mathrm{CS} 4 / \mathrm{n}=9)$; suplementado sedentário semana 4 (SS4 / $n=10)$; controle treinado semana 4 (CT4 / $n=6)$; suplementado treinado semana $4($ ST4 / $n=8)$; controle sedentário semana 8 (CS8 / $n=10)$; suplementado sedentário semana $8(S S 8 / n=8)$; controle treinado semana $8(C T 8 / n=7)$; suplementado treinado semana $8(S T 8 / n=7)$.

\section{Análises séricas e musculares}

A dosagem glicêmica foi realizada utilizando-se o glicosímetro Accu-Chek Advantage II (Roche").

As análises do glicogênio foram feitas em duas etapas: extração(11) e quantificação(12). A extração, segundo do método de Sjorgreen et al.(11), era feita através de amostras de tecidos $(0,265 \pm 0,015 \mathrm{mg})$ do músculo gastrocnêmio e fígado. Elas eram digeridas em tubos de vidro contendo solução de 30\% de hidróxido de potássio $(\mathrm{KOH})$ em banho fervente por 60 minutos. Após esse período foi adicionada, em cada tudo de ensaio, solução saturada de sulfato de sódio $\left(\mathrm{Na}_{2} \mathrm{SO}_{4}\right)$ e etanol a 70\%, sendo os tubos agitados no vórtex (AP 56, São Paulo, Brasil) e retornados ao banho-maria (Fanen, São Paulo, Brasil) por 15 minutos. Na seqüência, os tubos eram centrifugados (centrífuga 
Hettiche, Berlim, Alemanha), o sobrenadante era descartado e ao precipitado era acrescentado etanol a 70\%, sendo os tubos novamente agitados no vórtex. Repetia-se o processo de centrifugação e descarte do sobrenadante e adicionava-se $1 \mathrm{~mL}$ de água destilada quente para ressuspender o precipitado. A solução dessa vez era guardada para ser quantificada.

A quantificação era realizada utilizando o método de Hassid e Albrahams ${ }^{(12)}$, no qual, após cinco soluções-padrão serem preparadas, com diferentes concentrações de glicose, amostras de 50 $\mu \mathrm{L}$ e $10 \mu \mathrm{L}$ (gastrocnêmio e fígado, respectivamente) da solução proveniente da

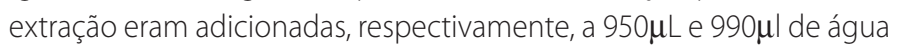
destilada e $2 \mathrm{~mL}$ de antrona (corante que se liga à glicose). Para formar

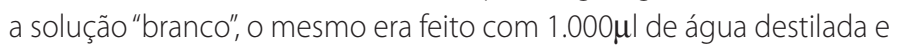
$2 \mathrm{~mL}$ de antrona; enquanto as soluções-padrão também eram formadas a partir de $1.000 \mu \mathrm{L}$ de cada diluição padrão adicionados a $2 \mathrm{~mL}$ de antrona. As amostras eram agitadas no vórtex e permaneciam por 15 minutos em banho fervente. Em seguida, eram retiradas do banhomaria e levadas ao espectrofotômetro (Dr. Lange Cadas 100, Berlim, Alemanha), que realizava a leitura com comprimento de onda de 650 nanômetros.

O espectro era zerado com o branco e as leituras das amostras eram feitas em duplicatas. Para o cálculo do glicogênio eram utilizadas a média da leitura das duplicatas e uma fórmula específica que gerou os resultados em miligramas de glicogênio por 100 miligramas de tecido.

\section{Análise estatística}

Utilizou-se a análise de variância para medidas repetidas (General Linear Model [GLM]) para a análise dos valores de glicogênio. Para as análises dos pontos da curva do TOTG, aplicou-se teste de normalidade de Shapiro-Wilk ou análise de variância (GLM), de acordo com a normalidade dos dados, e teste post-hoc de Tukey, para comparações múltiplas. O nível de significância adotado foi de $p \leq 0,05$ e foram utilizados os programas de computador Minitab e SAS, nas versões 14 e 8,02 respectivamente.

\section{RESULTADOS}

Houve uniformidade de peso entre os grupos no período basal, indicando homogeneidade. No decorrer do estudo, o ganho de peso médio entre os grupos também foi similar (figura 2).

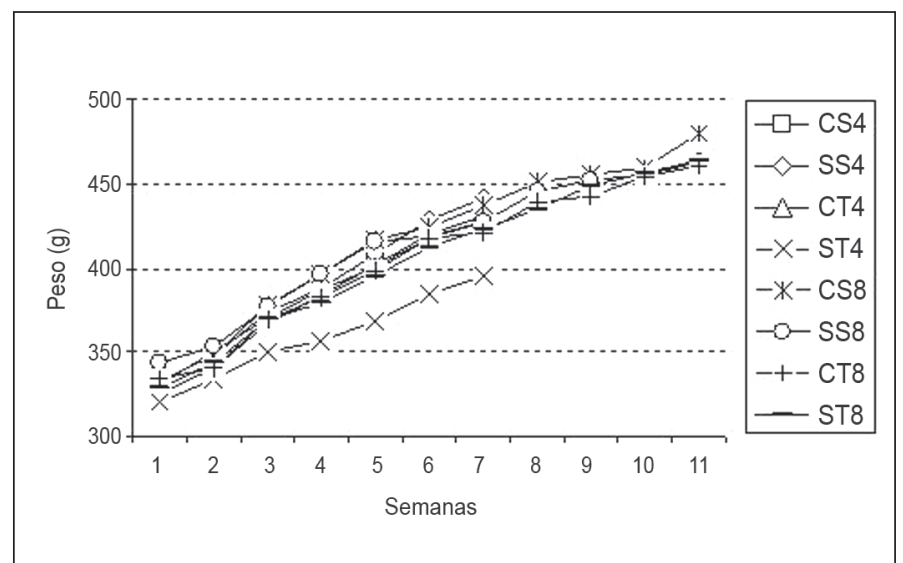

Figura 2. Curva de ganho de peso médio dos diferentes grupos. Grupos: controle sedentário semana 4 (CS4 / $n=9$ ); suplementado sedentário semana 4 (SS4 / $n=10$ ); controle treinado semana $4($ CT4 / $n=6)$; suplementado treinado semana 4 (ST4 / $n$ = 8); controle sedentário semana $8(\mathrm{CS} 8 / \mathrm{n}=10)$; suplementado sedentário semana 8 (SS8 / $n=8)$; controle treinado semana 8 (CT8 / $n=7)$; suplementado treinado semana 8 (ST8 / $n=7)$.
Não houve alteração significativa entre ou intragrupos em relação aos conteúdos de glicogênio hepático e muscular (tabela 1).

Tabela 1. Conteúdo de glicogênio muscular e hepático em função das intervenções

\begin{tabular}{c|c|c}
\hline Grupo & Gastrocnêmio & Fígado \\
\hline CS4 & $0,348 \pm 0,11$ & $3,478 \pm 0,84$ \\
\hline SS4 & $0,367 \pm 0,08$ & $3,091 \pm 0,39$ \\
\hline CT4 & $0,403 \pm 0,06$ & $3,204 \pm 0,73$ \\
\hline ST4 & $0,327 \pm 0,08$ & $2,911 \pm 0,46$ \\
\hline CS8 & $0,281 \pm 0,08$ & $2,646 \pm 0,69$ \\
\hline SS8 & $0,299 \pm 0,04$ & $2,987 \pm 0,22$ \\
\hline CT8 & $0,304 \pm 0,06$ & $2,687 \pm 0,37$ \\
\hline ST8 & $0,330 \pm 0,02$ & $2,680 \pm 0,30$ \\
\hline
\end{tabular}

Valores expressos em média e desvio-padrão de miligramas (mg) de glicogênio por $100 \mathrm{mg}$ de tecido. Controle sedentário semana 4 (CS4 / $n=9$ ); suplementado sedentário semana $4(S S 4 / n=10)$; controle treinado semana $4(C T 4 / n=6)$; suplementado treinado semana $4(\mathrm{ST} 4 / \mathrm{n}=8)$; controle sedentário semana $8(\mathrm{CS} 8 / \mathrm{n}=10)$; suplementado sedentário semana $8(\mathrm{SS} 8 / \mathrm{n}=8)$; controle treinado semana 8 (CT8 / $n=7)$; suplementado treinado semana $8(S T 8 / n=7)$.

Também não foram verificadas respostas significantemente diferentes em relação ao teste oral de tolerância à glicose entre os subgrupos (figura 3).

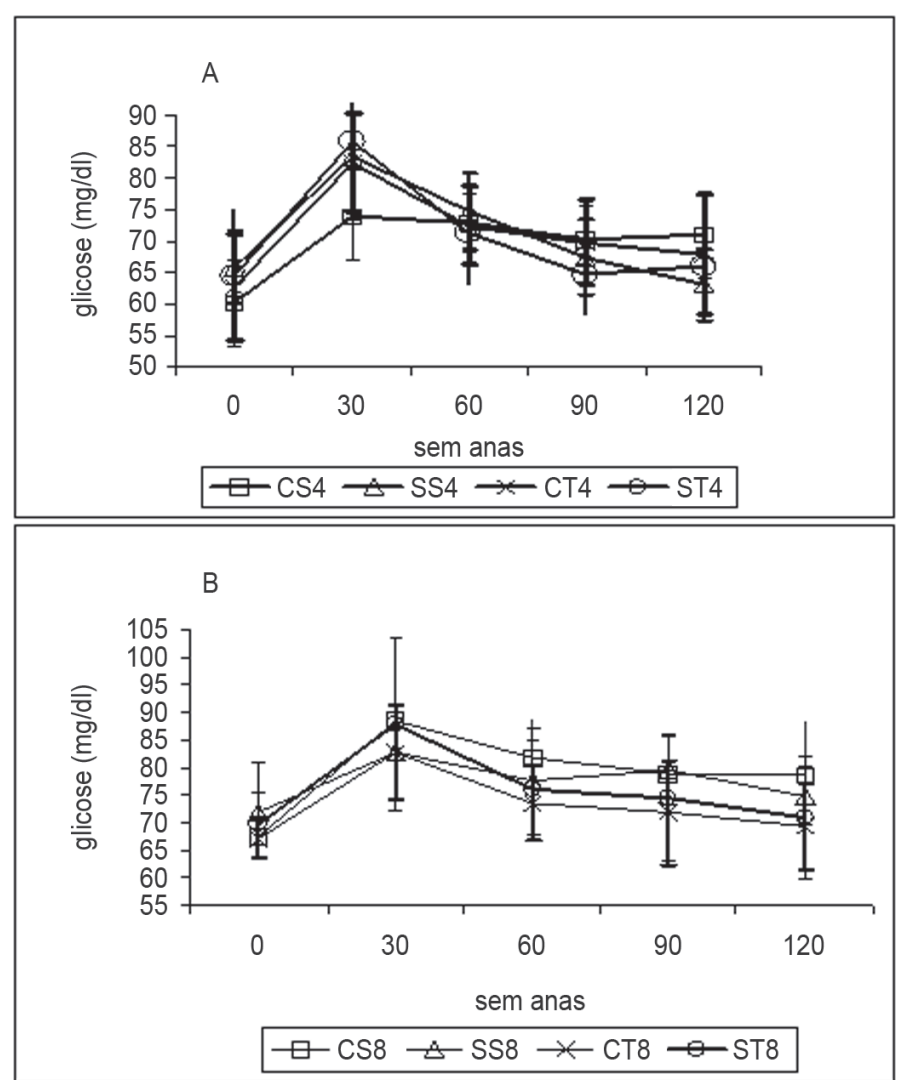

Figura 3. Glicemia dos ratos provenientes dos subgrupos da semana 4 (painel A) e 8 (painel B) em resposta ao TTG. Dados expressos em média e desvio-padrão. controle sedentário semana 4 (CS4 / $n=9$ ); suplementado sedentário semana 4 (SS4 / $n=10)$; controle treinado semana 4 (CT4 / $n=6$ ); suplementado treinado semana 4 (ST4 / $n$ = 8); controle sedentário semana 8 (CS8 / $n=10)$; suplementado sedentário semana $8(5 S 8 / n=8)$; controle treinado semana $8(C T 8 / n=7)$; suplementado treinado semana $8(S T 8 / n=7)$. 


\section{DISCUSSÃO}

O objetivo deste estudo foi investigar o efeito da suplementação de creatina na tolerância à glicose e nos estoques de glicogênio muscular e hepático em ratos submetidos ou não à atividade física por quatro e oito semanas. Utilizamos três fatores (suplementação, tempo e exercício) que pareciam interferir na homeostasia da glicose, mas que não apresentam resultados consensuais na literatura. Nossa hipótese era de que a suplementação de creatina aumentaria os estoques de glicogênio e melhoraria a tolerância à glicose, especialmente em ratos submetidos à atividade física. No entanto, nem o conteúdo de glicogênio dos tecidos, nem a resposta à sobrecarga oral de glicose foram afetados pelo desenho experimental adotado.

Na literatura tem sido amplamente demonstrado que a suplementação de creatina na ração, numa razão de 2\%, é capaz de promover aumento significativo da concentração de fosfocreatina (PCr) e creatina $(\mathrm{Cr})$ em tecidos de ratos ${ }^{(13,14)}$. McMillen et al. ${ }^{(14)}$, por exemplo, utilizaram essa quantidade de creatina; observaram aumento significativo no conteúdo total de creatina no músculo gastrocnêmio dos animais em apenas duas semanas de suplementação. Por isso, consideramos que a quantidade do suplemento empregada em nosso trabalho dificilmente não promoveria aumento nas concentrações de creatina nos tecidos dos animais, apesar de não termos medido esse parâmetro. Curiosamente, mesmo que considerássemos a hipótese de o suplemento não ter sido incorporado aos tecidos dos animais, alguns autores já sugeriram que outros fatores, diferentes da concentração de $\mathrm{PCr}$ e $\mathrm{Cr}$, poderiam afetar a homeostasia da glicose. Jeong-Sun et al. ${ }^{(7)}$ utilizaram o mesmo protocolo de suplementação por três semanas em ratos Wistar e, apesar de não observarem alterações nas concentrações musculares de PCr e Cr, constataram aumento significativo do conteúdo de GLUT-4, fosforilação da proteína quinase ativada por AMP (AMPK) e aumento em 40\% dos estoques de glicogênio no músculo epitroclear. Portanto, não consideramos que os nossos resultados foram influenciados pelo método de suplementação dos animais.

A influência do período de suplementação sobre a homeostasia da glicose foi outro fator que tentamos elucidar em nosso trabalho. Apesar de Op `t Eijnde et al. ${ }^{(6)}$ demonstrarem aumento do conteúdo de glicogênio muscular em ratos utilizando altíssimas doses de creatina em apenas cinco dias, Rooney et al. ${ }^{(5)}$ só conseguiram observar efeitos sobre a insulinemia e tolerância à glicose após quatro e oito semanas, respectivamente. No nosso estudo, o tempo de suplementação não exerceu qualquer influência sobre os parâmetros investigados.

Um fator que pode ter contribuído para nossos resultados foi o tipo de músculo escolhido para a análise. Na literatura, os estudos divergem quanto aos tipos de músculo utilizados para avaliar a influencia da suplementação de creatina na captação de glicose e conteúdo de glicogênio ${ }^{(5,7)}$. Baseados no fato de as fibras de característica anaeróbia possuírem maior conteúdo de glicogênio, PCr e adenosina trifosfato (ATP), em comparação com aeróbias, escolhemos o músculo gastrocnêmio para as dosagens do glicogênio. Esse músculo, ainda que de característica mista, possui aproximadamente 93\% de seu conteúdo de fibras do tipo II (glicolíticas) ${ }^{(15)}$. Mesmo assim, não observamos aumento significativo do conteúdo de glicogênio muscular após a suplementação com a creatina, corroborando estudos prévios que utilizaram músculos caracterizados pelo mesmo tipo de fibra muscular(5,6).

De fato, os estudos que reportaram aumento na concentração de glicogênio utilizaram músculos com alta capacidade oxidativa ${ }^{(6,7)}$. Dessa forma, as discrepâncias poderiam justificar-se pelas diferenças nas características dos músculos adotados.
Outro fator que pode ter influenciado nos resultados foi o tipo de exercício físico adotado. Em humanos, a suplementação de creatina tem sido associada aos aumentos no conteúdo de GLUT-4 e estoques de glicogênio muscular, especialmente quando combinada à prática de atividade física ${ }^{(8)}$. Reconhecidamente, o exercício físico per se é capaz de afetar a captação de glicose, aumentando seu transporte para dentro da célula, mediado por maior translocação do GLUT-4 para a membrana plasmática, mesmo sem a presença da insulina ${ }^{(16)}$. Considerando esse mecanismo, e pelo fato de não termos verificado diferenças nas concentrações de glicogênio muscular entre os grupos sedentários e exercitados, ponderamos a hipótese de nosso treinamento não ter sido suficientemente intenso (volume e/ou duração) para promover as adaptações capazes de gerar maior captação de glicose nos tecidos. Nos estudos que verificaram alterações nas concentrações de glicogênio muscular, em ratos submetidos ao treinamento de natação, os autores utilizaram volume muito maior de exercício (duas sessões de três horas de natação, separadas por 45 minutos de intervalo) que o nosso ${ }^{(17-19)}$. Paralelamente, outro aspecto que vale a pena ser ressaltado é que, após uma sessão de depleção de glicogênio muscular, como resposta adaptativa, ocorre aumento do conteúdo de GLUT-4 para promover maior captação de glicose pelas células ${ }^{(17)}$. Considerando que essa resposta adaptativa só cessa completamente após 48 horas $^{(20)}$, poderíamos inferir que, se o exercício realizado na segunda-feira das semanas quatro e oito fossem realmente eficazes na redução do conteúdo de glicogênio muscular, poderíamos observar queda mais acentuada na curva do TOTG realizado na terça feira, ao menos nos ratos submetidos à atividade física. No entanto, nenhuma diferença foi observada entre os subgrupos, o que favorece a possibilidade de o protocolo de exercício adotado realmente não ter sido eficaz na promoção das adaptações necessárias para promover maior captação de glicose.

Caso os efeitos da suplementação de creatina sejam apenas existentes quando combinados ao exercício físico, é possível especular que nossos achados são conseqüência da incapacidade do protocolo de treinamento em gerar adaptações no metabolismo glicídico, em detrimento da hipótese de a creatina não ser efetiva para tal finalidade. Essa possibilidade parece ser bastante plausível, já que alguns grupos, incluindo o nosso, demonstraram o efeito sinérgico da creatina ao exercício na captação de glicose $\mathrm{e}^{(3,6,21)}$.

Em suma, a suplementação de creatina não influenciou a captação periférica de glicose e os estoques de glicogênio muscular e hepático em ratos submetidos à atividade física por quatro e oito semanas. Ressaltamos ainda que os achados discrepantes na literatura podem, parcialmente, ser atribuídos às grandes diferenças metodológicas utilizadas nos estudos. Portanto, mais estudos devem ser realizados no intuito de elucidar os possíveis efeitos da suplementação de creatina na homeostase da glicose, sobretudo no que se refere a sua possível aplicação terapêutica.

\section{AGRADECIMENTOS}

Agradecemos aos membros do Laboratório de Nutrição Aplicado a Atividade Motora da EEFUSP, pela ajuda durante os experimentos, ao Professor Dr. Julio Tirapegui, por ter cedido seu laboratório para as análises de glicogênio, e à Ivanir Pires, pelo cuidado, presteza e auxílio durante essas dosagens.

Todos os autores declararam não haver qualquer potencial conflito de interesses referente a este artigo. 


\section{REFERÊNCIAS BIBLIOGRÁFICAS}

1. Terjung RL, Clarkson P, Eichner ER, Greenhaff PL, Hespel PJ, Israel RG, et al. American College of Sports Medicine roundtable. The physiological and health effects of oral creatine supplementation. Med Sci Sports Exerc 2000;32:706-17.

2. Ferrante RJ, Andreassen OA, Jenkins BG, Dedeoglu A, Kuemmerle S, Kubilus JK, et al. Neuroprotective effects of creatine in a transgenic mouse model of Huntington's disease. J Neurosc 2000;20:4389-97.

3. Gualano B, Novaes RB, Artioli GG, Freire TO, Coelho DF, Scagliusi FB, et al. Effects of creatine supplementation on glucose tolerance and insulin sensitivity in sedentary healthy males undergoing aerobic training. Amino Acids (in press).

4. Arciero PJ, Hannibal NS 3rd, Nindl BC, Gentile CL, Hamed J, Vukovich MD. Comparison of creatine ingestion and resistance training on energy expenditure and limb blood flow. Metabolism 2001:50:1429-34.

5. Rooney K, Bryson J, Phuyal J, Denyer G, Caterson I, Thompson C. Creatine supplementation alters insulin secretion and glucose homeostasis in vivo. Metabolism 2002;51:518-22.

6. Op't Eijnde B, Urso B, Richter EA, Greenhaff PL, Hespel P. Effect of oral creatine supplementation on human muscle GLUT4 protein content after immobilization. Diabetes 2001;50:18-23.

7. Ju JS, Smith JL, Oppelt PJ and Fisher JS. Creatine feeding increases GLUT4 expression in rat skeletal muscle. Am J Physiol Endocrinol Metab 2005;288:E347-52.

8. Derave W, Eijnde BO, Verbessem P, Ramaekers M, Van Leemputte M, Richter EA, et al.. Combined creatine and protein supplementation in conjunction with resistance training promotes muscle GLUT-4 content and glucose tolerance in humans. J Appl Physiol 2003;94:1910-6.

9. Newman JE, Hargreaves M, Garnham A, Snow RJ. Effect of creatine ingestion on glucose tolerance and insulin sensitivity in men. Med Sci Sports Exerc 2003;35:69-74

10. Van Loon $L$, Murphy R, Oosterlaar AM, Cameron-Smith D, Hargreaves M, Wagenmakers AJ, et al. Creatine supplementation increases glycogen storage but not GLUT-4 expression in human skeletal muscle. Clin Sci (Lond) 2004;106:99-106
11. Sjorgreen B, Nordenksjold T, Holmgren H, Wollerstron J. Beitrag Kentnis des lebenrhythmik. Pflügers Arch Gesant Physiol Mensch Ticre 1938;240-7.

12. Hassid WZ, Albrahams S. Chemical Procedures for analyses of polisacchardies methods enzimo 1957;3:34-51.

13. Brannon TA, Adams GR, Conniff CL, Baldwin KM. Effects of creatine loading and training on running performance and biochemical properties of rat skeletal muscle. Med Sci Sports Exerc 1997;29:489-95.

14. McMillen J, Donovan CM, Messer JI, Willis WT. Energetic driving forces are maintained in resting rat skeletal muscle after dietary creatine supplementation. J Appl Physiol 2001;90:62-6.

15. Armstrong RB, Phelps RO. Muscle fiber type composition of the rat hindlimb. Am J Anat 1984;171:259-72

16. Pereira LO, Lancha Jr AH. Effect of insulin and contraction up on glucose transport in skeletal muscle. Prog Biophys Mol Biol 2004;84:1-27.

17. Garcia-Roves PM, Han DH, Song Z, Jones TE, Hucker KA, Holloszy JO. Prevention of glycogen supercompensation prolongs the increase in muscle GLUT4 after exercise. Am J Physiol Endocrinol Metab 2003;285:E729-36.

18. Nakatani A, Han DH, Hansen PA, Nolte LA, Host HH, Hickner RC, et al. Effect of endurance exercise training on muscle glycogen supercompensation in rats. J Appl Physiol 1997;82:711-5.

19. Ren JM, Semenkovich CF, Gulve EA, Gao J, Holloszy JO. Exercise induces rapid increases in GLUT4 expression, glucose transport capacity, and insulin-stimulated glycogen storage in muscle. J Biol Chem 1994;269:14396-401

20. Host HH, Hansen PA, Nolte LA, Chen MM, Holloszy JO. Glycogen supercompensation masks the effect of a traininginduced increase in GLUT-4 on muscle glucose transport. J Appl Physiol 1998:85:133-8.

21. Op't Eijnde B, Jijakli H, Hespel P, Malaisse WJ. Creatine supplementation increases soleus muscle creatine content and lowers the insulinogenic index in an animal model of inherited type 2 diabetes. Int J Mol Med 2006;17:1077-84. 